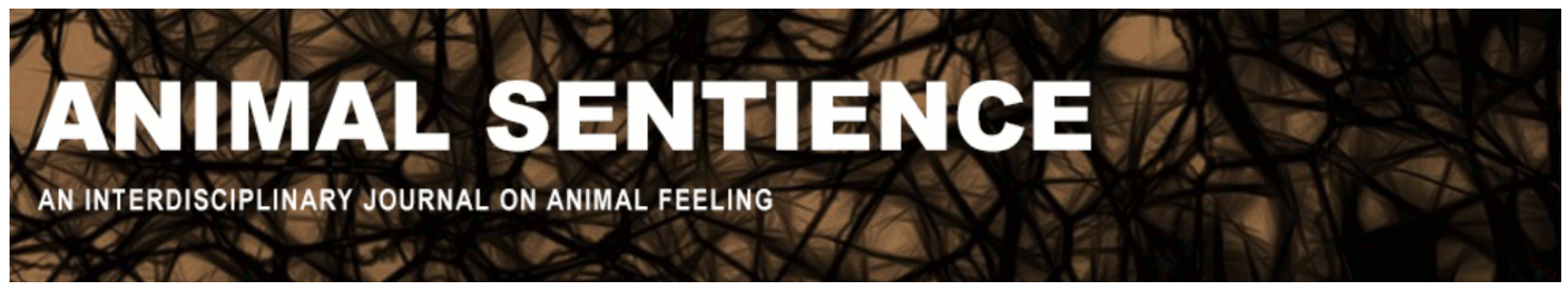

Forber, Patrick and Jones, Robert C (2020) Spineless and sentient: a challenge for moral comparison. Animal Sentience 29(30)

DOI: $10.51291 / 2377-7478.1606$

Date of submission: 2020-06-30

Date of acceptance: 2020-07-17

(c)

This article has appeared in the journal Animal

Sentience, a peer-reviewed journal on animal

cognition and feeling. It has been made open access,

free for all, by WellBeing International and deposited

in the WBI Studies Repository. For more information,

please contact

wbisr-info@wellbeingintl.org.

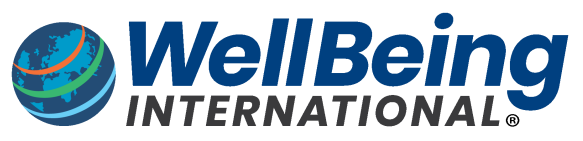

SOLUTIONS FOR PEOPLE, ANIMALS AND ENVIRONMENT 


\title{
Spineless and sentient: a challenge for moral comparison
}

Commentary on Mikhalevich \& Powell on Invertebrate Minds

\author{
Patrick Forber \\ Department of Philosophy, Tufts University \\ Robert C. Jones \\ Department of Philosophy, California State University, Dominguez Hills
}

\begin{abstract}
We agree with Mikhalevich \& Powell but take issue with their criteria for attributing sentience. This problem is connected with difficult issues concerning moral comparisons and evaluating moral decisions when interspecific moral interests conflict.
\end{abstract}

Patrick Forber, Associate Professor of Philosophy at Tufts University, has published extensively in philosophy and biology journals about evidence, adaptationism, game theory, and social behavior. Website

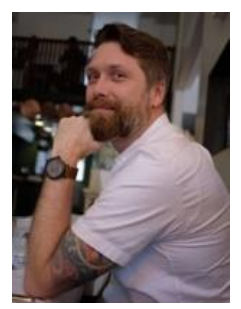

Robert C. Jones, Associate Professor of Philosophy at California State University, Dominguez Hills, co-author of Chimpanzee Rights (Routledge 2018), has published on animal ethics, animal cognition and food ethics and has given over fifty talks on animal rights. Website

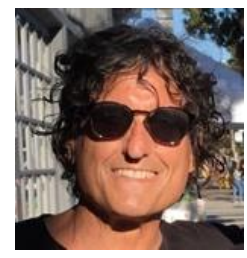

Mikhalevich \& Powell (2020) (M\&P) present an interesting argument for reconsidering our moral attitudes towards invertebrates. It leans on (a) recent empirical research about the cognitive capabilities of invertebrates, (b) philosophical concerns about the heterogeneity of invertebrates, and (c) human biases in assessing the strange ways of invertebrate life. We largely agree with M\&P but have a concern about measuring welfare and weighing conflicting interests in moral calculations, especially regarding some invertebrates.

1. How to attribute sentience? M\&P make a clear declaration about the circumstances under which attributing sentience is justified:

"Until we have a fully worked out and empirically corroborated theory of the relationships among neural tissue, cognitive processes, and phenomenology, we are not in a position to rule out or even deem unlikely the possibility that tiny brains can give rise to sentient lives with interests that merit moral protection."

Let us call this the "Theoretical and Empirical Requirement of Sentience Attribution" (TERSA). We agree that ruthless application of Occam's razor to eliminate mental states and sentience in 
nonhuman animals should be resisted but we think TERSA is (i) too demanding and a (ii) a doubleedged sword.

(i) TERSA is too demanding. The scientific community does not even have a consensus theory of sentience for humans, the great apes, or cetaceans, let alone cephalopods or insects. Surely we can make inferences about the (non) existence and nature of mental states of nonhumans without demanding such consensus. M\&P would probably agree. But the real problem with using TERSA as a sort of benchmark is that it can cut both ways.

(ii) TERSA is a double-edged sword. Consider a converse version of the thesis, TERSAminus: "Until we have a fully worked out and empirically corroborated theory of the relationships among neural tissue, cognitive processes, and phenomenology we are not in a position to entertain or even deem likely the possibility that tiny brains can give rise to sentient lives with interests that merit moral protection." If TERSA is true, why not TERSA-minus?

Why is such a well-worked-out theory and its empirical corroboration needed to prevent us from eliminating the possibility of sentience in nonhuman animals but not required for conferring sentience on them? If something like TERSA is true, then we should be agnostic about the mental lives of, say, arthropods.

One way to accept TERSA but block TERSA-minus would be to adopt a robust precautionary principle (PP). We suspect M\&P's argument presumes some version of PP. The trouble is that this is in tension with critical comments M\&P make later about the vagueness of PPs, and about problems with Birch's (2017) specific application of PP to animal sentience. M\&P (rightly) point out a problem for many versions of PP: there are costs associated with precautionary measures, often in terms of the interests or well-being of other morally considerable entities. If precautions were cost-free, we would demand the highest standards of safety for any moral hazard. This is the thrust of Sunstein's $(2003,2018)$ critique of PP as part of his defense of cost-benefit analysis.

M\&P conclude their discussion of PP by claiming that if the costs of precaution are substantial, "we have strong moral incentive to get the attribution of sentience right; extreme positions that require either very high or very low levels of certainty ought to be rejected." TERSA-minus requires a very high level of certainty to attribute sentience. Conversely, TERSA requires a very low level of certainty to attribute sentience: We cannot eliminate the hypothesis that arthropods are sentient without a complete theory of the mind.

2. A measurement problem. We do need to get the attributions of sentience right in order to tackle a deeper philosophical problem: how do we measure and compare moral interests and welfare? More pressingly: how do we adjudicate conflicts of moral interest between species (cf. Treves et al. 2019)? Anyone who has taken a drive down a rural highway on a summer night has committed arthropod slaughter. If arthropods are indeed sentient, we need some sort of moral calculus to evaluate when we are compromising their moral interests and under what circumstances it is permissible to do so. The proportion of arthropod biomass on Earth is over 
sixteen times that of human biomass and obviously individual arthropods have an average mass much less than individual humans (Bar-On et al. 2018). They outnumber us in dramatic fashion. ${ }^{1}$

It is known to be difficult to make Intersubjective comparisons of utility work, yet they are the foundation of any resolution of conflicts of interest between morally considerable entities (cf. Narens \& Skyrms 2018; Skyrms \& Narens 2019). Human interpersonal comparisons are the "easiest" case because we each have an intimate perspective on what it is like to be a human with moral interests-yet we lack a consensus even for that case. Expanding the moral circle (which we support) involves bringing nonhumans into the space of moral considerability, but without the same intimate perspective on their inner lives.

We can still make progress, especially on closely related species such as chimps or other great apes (Andrews et al 2018). This is a comparison facilitated by evolutionary homology. Being bipedal mammals who split with the chimp lineage several million years ago helps give humans a sense of their moral interests. But as we range farther afield across the evolutionary tree, we lose this traction. It may be impossible to evaluate the moral interests of bees independently from the moral interests of their colonies (Monsó \& Osuna-Mascaró 2020). Questions about the moral interests of invertebrates become entangled with puzzles about biological individuality, further complicating the moral calculus. Such challenges need to be met before one can advise policy makers or moral actors.

\section{References}

Andrews K, Comstock GL, Crozier GKD, Donaldson S, Fenton A, John TM, Johnson LSM, Jones RC, Kymlicka W and Meynell L (2018) Chimpanzee rights: The philosophers' brief. Routledge.

Bar-On Y M, Phillips R \& Milo R (2018) The biomass distribution of Earth. Proceedings of the National Academy of Sciences 115(25):6506-6511.

Birch J (2017) Animal sentience and the precautionary principle. Animal Sentience: An Interdisciplinary Journal on Animal Feeling 16(1).

Mikhalevich, Irina \& Powell, Russell (2020) Minds without spines: Evolutionarily inclusive animal ethics. Animal Sentience 29(1)

Narens L and Skyrms B (2018) Accomodation dynamics for comparing utilities with others. Philosophical Studies 175:2419-2427.

Monsó S and Osuna-Mascaró A J (2020) Problems with basing insect ethics on individuals' welfare Animal Sentience 29(8).

Skyrms B \& Narens L (2019) Measuring the hedonimeter. Philosophical Studies. 176(12): 31993210.

Sunstein C (2003) The Paralyzing Principle: Does the Precautionary Principle Point us in any Helpful Direction? Regulation, Winter 20022003.

Sunstein C (2018) The Cost-Benefit Revolution. MIT Press

Treves, Adrian; Santiago-Ávila, Francisco J.; and Lynn, William S. (2019) Just preservation. Animal Sentience 27(1)

\footnotetext{
${ }^{1}$ We focus on the utilitarian version of the problem although the reasoning generalizes to other ethical frameworks.
} 